has been found so far $(a)$ in cases with adrenogenital syndrome (pseudo-hermaphroditism), $(b)$ in arrhenoblastoma, $(c)$ in the last months of pregnancy. Excretion increased following injection of $300 \mathrm{mgm}$. of adrenotropic hormone over a period of three days.

The chemical constitution of the fluorescent substance or substances of the neutral fraction-probably of adrenal cortical origin-are being studied in collaboration with Prof. T. Reichstein of Basle.

We are much indebted to Miss L. Berlin, Mr. A. Schwager and Mrs. L. Beyth for their assistance. This investigation has been aided by a grant from the Jane Coffin Childs Memorial Fund for Medical Research.

Hormone Research Laboratory,

Bernhard ZondeK

MiCHAEL FINKELSTEIN

Hebrew University-Hadassah Medical School, Jerusalem. June 5.

${ }^{1}$ Finkelstein, M., Hestrin, S., and Koch, W., Proc. Soc. Exp. Biol. and Med., 64, 64 (1947).

2 Finkelstein, M., Proc. Soc. Exp. Biol. and Med., 69, 181 (1948).

\section{A Method for Administering Chemotherapeutic Agents to Chick Embryos}

The technique described was developed for the purpose of studying the action of chemotherapeutic agents, given in divided doses by the yolk-sac route, on the proliferation of vaccinia virus in embryonated eggs.

A glass needle is prepared by drawing out a piece of tubing of approximately $6 \mathrm{~mm}$. internal diameter to a capillary $4 \cdot 0-4 \cdot 5 \mathrm{~cm}$. long. The wide end of the tube is cut off $1.0 \mathrm{~cm}$. from the point of narrowing, and the capillary end is bevelled to a sharp point on the flat surface of a rotating 'Carborundum' dental disk. (It is advisable to wear an eye-shield during this operation.) The wide end of the needle is closed with a small rubber vaccine-bottle cap. A number of these assemblies are prepared and autoclaved.

11-Day embryonated eggs are candled, and a point marked in the centre of the long axis where the chorio-allantois is well developed, but as far from the embryo as possible. A triangle of shell is cut away from this point, the shell membrane is pierced, and the chorio-allantoic membrane is 'dropped' by suction through a hole drilled into the natural airsac. The yolk-sac can then be seen lying directly beneath the opening.

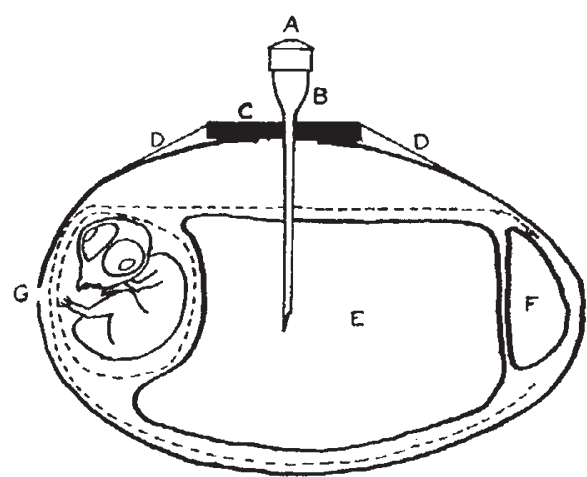

Longitudinal sectional diagram of 11-day embryonated egg with glass needle implanted in yolk-sac. $A$, rubber vaccine-bottle cap; $B$, glass needle ; $C$, rubber disk $; D, D$, adhesive tape $; E$, yolk-
The glass needle, which has been forced for about $3 \mathrm{~cm}$. of its length through the centre of a sterile rubber disk of the type used in 1-oz. 'Universal Container' caps $(2.75 \mathrm{~cm}$. in diameter $)$, is next inserted through the chorio-allantoic membrane, and into the yolk-sac, until the rubber disk rests upon the shell, to which it is then secured with strips of adhesive tape (see diagram). One worker, with an assistant to drill the eggs, can set up thirty to forty such preparations within an hour.

The chorio-allantois can be infected with the test virus before insertion of the glass needle, or afterwards by injection with a fine hypodermic needle through the rubber disk.

Injections of the chemotherapeutic agent can now be made at desired intervals through the vaccine cap with a hypodermic syringe. The small quantity of fluid remaining in the glass needle after injection is expelled into the yolk-sac by the further injection of a small quantity of air. Up to $1.0 \mathrm{ml}$. of fluid may be thus administered in divided doses.

At the end of the experiment, the glass needle is withdrawn, the rubber disk removed, and the egg opened for examination. The interference with the chorio-allantois is minimal. A small hole surrounded by a very small area of tissue reaction will be seen where the needle has passed through. The embryos tolerate this procedure remarkably well; in our hands deaths attributable to inoculation trauma have amounted to less than 5 per cent of the total treated, in experiments lasting $48-72 \mathrm{hr}$.

The advantages claimed for this method are: (a) the chemotherapeutic agent is not given by the same route as the virus, thus obviating any direct virucidal action ; $(b)$ repeated injections may be given under completely sterile conditions, maintaining a high concentration of test agent in the tissues; (c) the injections are placed in the yolk-sac with absolute precision, especially in older embryos in which the usual injection route via the air-sac is not always satisfactory; (d) repeated doses may be given to large numbers of embryos with rapidity.

L. H. Collier

Lister Institute of Preventive Medicine, Elstree, Herts. July 27.

\section{Isolation of $2: 3: 4: 6$-Tetramethylpyridine from Coal Tar}

DURING an investigation, previously referred to ${ }^{1}$, of the nitrogenous bases extracted by sulphuric acid from the 'benzol absorbing oil' fraction of vertical retort coal tar, a tertiary base has been isolated which has been proved to be $2: 3: 4: 6$-tetramethylpyridine, a compound which has not hitherto been reported as a constituent of coal tar. This compound, however, has been previously isolated from Fushun shale oil by Eguchi ${ }^{2}$, and from Scottish shale oil by Benzie and Milne ${ }^{3}$.

The base was isolated from a fraction (boiling point $135-135 \cdot 2^{\circ} \mathrm{C} .100 \mathrm{~mm}$.) obtained by highefficiency fractional distillation (efficiency approximately 100 theoretical plates) as follows. The fraction was treated with the theoretical amount of picric acid in three equal portions, the picric acid being added as a saturated alcoholic solution. In this way three batches of picrate were obtained, the first two of which melted at $110-120^{\circ} \mathrm{C}$. and con- 